\title{
Wide Excision without Radiation as Primary Treatment for Breast Cancer in Older Patients
}

\author{
Gregory P. Swanson ${ }^{*}$, Elaine Lagow ${ }^{2}$, Mark Riggs ${ }^{3}$ and Richard Symmonds ${ }^{4}$ \\ ${ }^{I}$ The University of Texas Health Science Center San Antonio, USA \\ ${ }^{2}$ Baylor University Medical Center Dallas, USA \\ ${ }^{3}$ Abilene Christian University, Abilene, Texas, USA \\ ${ }^{4}$ Scott and White Memorial Hospital and Clinic; Scott, Sherwood and Brindley Foundation; The Texas A\&M University \\ System Health Science Center College of Medicine; Temple, Texas, USA
}

\begin{abstract}
Introduction: Prior to the introduction of sentinel lymph node sampling, wide excision and axillary dissection followed by radiation to the breast was considered a standard treatment for breast cancer. Not all patients who undergo breast conserving surgery receive radiation therapy, which is considered suboptimal care. We have evaluated our experience with wide excision alone and its effect on local-regional recurrence, development of metastatic disease and survival.

Materials and Methods: Between 1987-1997 we identified 69 patients (70 breasts) treated with wide excision without radiation for their primary breast cancer.

Results: The median age at diagnosis was 79 years. Median follow-up was 6.7 years. The median tumor size was $1.1 \mathrm{~cm}$ (range $0.2-3.5 \mathrm{~cm}$ ). Fifty three percent of the patients received tamoxifen. Tumor size was significant for failure and survival. Seven $(10 \%)$ patients failed. Only 6 patients $(9 \%)$ had an ipsilateral recurrence requiring surgical intervention. Two of the six developed metastatic disease. One additional patient had distant spread without a detected local failure. Overall, 3 (4\%) developed metastatic disease and died with breast cancer as a contributing factor. Sixty four percent of the patients died without contribution from the breast cancer, and $31 \%$ were alive without disease.

Conclusions: Not all patients require radiation for cancer control after wide excision. Patients who can be considered for surgery alone without an unacceptable risk are the elderly (especially those with comorbid conditions with small low grade tumors treated with wide surgical margins).
\end{abstract}

Keywords: Breast cancer, wide excision, lumpectomy alone, breast conservation.

\section{INTRODUCTION}

With the publication and subsequent updates of the classic National Surgical Adjuvant Breast Project (NSABP) and Milan studies, it has been proven that survival is equivalent between mastectomy and wide excision followed by radiation in the treatment of breast cancer $[1,2]$. The NSABP B-06 study was one of several that looked at wide excision alone. In that study, in-breast recurrence rates were $40 \%$ without radiation [1]. Despite this, it is still common for certain subgroups of patients, specifically the elderly, to not undergo radiation. The rationale is that the comorbidities that come with age will have an earlier and greater impact on survival than the risk of ipsilateral breast recurrence. We have reviewed our experience with women who were treated with wide excision without radiation for breast cancer. We sought a patient cohort with long enough follow up that the effect on survival could be determined.

*Address correspondence to this author at the University of Texas Health Science Center San Antonio, 7703 Floyd Curl Drive MC 7889, San Antonio, TX 78229-3900, USA; Tel: (210) 450-1109; Fax: (210) 450-5085; E-mail: swansong@uthscsa.edu

\section{MATERIALS AND METHODS}

Between 1987 and 1997, 1699 women were diagnosed with invasive breast cancer. Three hundred three patients were diagnosed with invasive breast cancer and underwent wide excision followed by radiation [3]. We identified an additional 69 patients who were treated with wide excision without radiation.

The decision to forgo radiation was made in discussion between the physician and the patient, often with her family. Generally, the deciding factor was advanced age with comorbid medical conditions. The median age was 79 years (range: $48-100$ years) at the time of diagnosis.

The practice policy was to do an excision for diagnosis, with subsequent wider excision for close $(<2 \mathrm{~mm})$ or positive margins. In this group of patients, 39 had close or positive margins and 19 were not re-excised after discussion between the patient and physician. Given the desire to do only that which was considered absolutely necessary, an axillary dissection was not performed in $53(76 \%)$ of the patients.

The plan was to follow patients every 4-6 months for the first 2 years, then every 6-12 months thereafter. In this elderly population, many of whom were in nursing homes, 
breast specific follow up with regular routine mammograms was not always performed. Problems were addressed as they arose, which reflects the reality of following this cohort of patients. Therefore, the endpoint is not the specifics of recurrence, but rather the morbidity of this approach to breast cancer treatment as opposed to mortality from the ravages of age. In short, the feeling in general is that the specifics of whether the patient had recurrence were not as important as whether there was morbidity from recurrence.

Failure was determined either mammographically, radiographically or on physical exam. Patients were scored as having ipsilateral breast recurrence or disseminated disease. Contralateral breast cancer was not considered a failure, since it is generally considered a new primary. If ipsilateral recurrence or contralateral disease was determined, the plan was for further surgery, usually mastectomy. One patient with contralateral breast cancer was again treated with wide excision alone, which accounts for 70 cancers in 69 patients that we followed.

Statistics: Continuous variables were summarized as median and range. Overall survival and disease-free survival were computed using Kaplan-Meier survival methods. Effects of tumor size and grade were tested using the logrank test. P-values less than 0.05 indicated statistically significant effects.

\section{RESULTS}

Median follow up was 6.7 years (range 0.1-14.2) for the entire cohort and median follow up of survivors was 9.4 years (except for the one patient lost to follow up, the minimum follow up of the survivors was 7.6 years). As shown in Table 1, the median size of the tumors was $1.1 \mathrm{~cm}$ (range $0.2-3.5 \mathrm{~cm}$ ). Patients with tumors $>1.5 \mathrm{~cm}$ were more likely to fail $(\mathrm{p}=0.01)$ and this adversely effected survival ( $\mathrm{p}=.03$ ), although the number of patients failing was small.

Of 17 patients (24\%) who underwent lymph node dissection, 15 were negative and 2 were positive. One patient had palpable nodes at presentation and had a delayed axillary dissection followed by axillary radiation when progression became evident.

All but 5 patients (7\%) underwent estrogen receptor determination and $84 \%$ were positive. All patients were considered for adjuvant systemic treatment. None were treated with chemotherapy and $37(53 \%)$ were started on tamoxifen.

Seven $(10 \%)$ patients failed. Only 6 patients $(9 \%)$ had an ipsilateral recurrence requiring surgical intervention. Two of the six developed metastatic disease. One additional patient had distant spread without a detected local failure. Overall, 3 (4\%) developed metastatic disease and died with breast cancer as a contributing factor. Sixty-four percent died without contribution from the breast cancer and $31 \%$ were alive without disease. Overall and disease free survival are shown in Fig. (1).

\section{DISCUSSION}

A seminal event in breast oncology was the proof that wide excision with radiation yields equivalent survival to mastectomy $[1,2]$. As a result, the National Cancer Institute
(NCI) consensus conference recommendations are that breast conservation is preferred to mastectomy in the treatment of breast cancer and the treatment should consist of wide excision and radiation therapy [4]. Despite these recommendations, there are still patients, especially the elderly, who do not receive the full complement of treatment; specifically post lumpectomy radiation. Several reports have decried the denial to the elderly of all the available therapies, the implication being that they are suffering as a consequence of not receiving appropriate treatment [5-9]. Most of those studies have not been able to show a survival decrement. In our study, the number of patients suffering a recurrence was very low, with low morbidity. As our data would indicate, it is becoming apparent that there may be patients who do not benefit from post lumpectomy radiation.

Table 1. Patient Characteristics $(\mathrm{N}=70$ Breasts in 69 Patients)

\begin{tabular}{|c|c|c|c|}
\hline & $\mathbf{N}$ & Median & Range \\
\hline Age & & 79 years & 48 to 100 years \\
\hline$<60$ & $3(4 \%)$ & & \\
\hline $60-69$ & $9(13 \%)$ & & \\
\hline $70-79$ & $24(34 \%)$ & & \\
\hline $80-89$ & $27(39 \%)$ & & \\
\hline 90 and older & $7(10 \%)$ & & \\
\hline Size & & $1.1 \mathrm{~cm}$ & 0.2 to $3.5 \mathrm{~cm}$ \\
\hline$<1.0 \mathrm{~cm}$ & $24(34 \%)$ & & \\
\hline 1.0 to $1.9 \mathrm{~cm}$ & $35(50 \%)$ & & \\
\hline 2.0 to $2.9 \mathrm{~cm}$ & $9(13 \%)$ & & \\
\hline 3.0 to $3.9 \mathrm{~cm}$ & $2(3 \%)$ & & \\
\hline \multicolumn{4}{|l|}{ ER Status } \\
\hline Positive & $59(84 \%)$ & & \\
\hline Negative & $6(9 \%)$ & & \\
\hline Not Done & $5(7 \%)$ & & \\
\hline \multicolumn{4}{|l|}{ Grade } \\
\hline 1 & $30(43 \%)$ & & \\
\hline 2 & $30(43 \%)$ & & \\
\hline 3 & $9(13 \%)$ & & \\
\hline Not done & 1 & & \\
\hline \multicolumn{4}{|l|}{ Follow-up } \\
\hline All patients & & $6.7 \mathrm{yrs}$ & 0.1 to $14.2 \mathrm{yrs}$ \\
\hline Survivors & & $9.4 \mathrm{yrs}$ & 0.4 to $13.6 \mathrm{yrs}$ \\
\hline \multicolumn{4}{|l|}{ Status at last FU } \\
\hline Alive, NED & $22(31 \%)$ & & \\
\hline Dead, NED & $45(64 \%)$ & & \\
\hline Dead, with ca & $3(4 \%)$ & & \\
\hline
\end{tabular}

In several of the randomized studies, there was a cohort of patients who were treated by wide excision without radiation. For example, in the NSABP B-06 study, patients 
receiving post excision radiation had an ipsilateral breast failure rate of $14 \%$. For those treated with wide excision alone, the rate was $39 \%$ [1]. These results are consistent among the various randomized and retrospective studies (Table 2). There is no argument that radiation can reduce the risk of failure, which demonstrates that the radiation is absolutely necessary for the most favorable outcome. The same is not true for survival. Even with long term follow up, in every randomized study, despite a higher rate of ipsilateral breast failure, the patients in the surgery alone groups have statistically the same survival rate as those in the surgery and radiation cohorts $[1,2]$. This would indicate that if there is survival decrement to an ipsilateral breast recurrence, it is small. There is still the psychological trauma of dealing with a local recurrence, but in the vast majority of the patients it is not a life-threatening disaster.

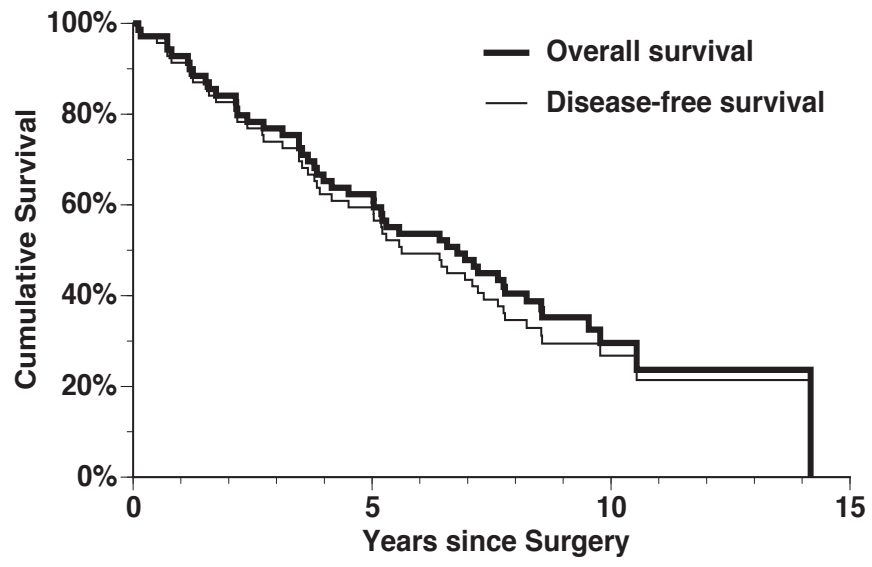

Fig. (1). Overall and Disease free survival for patients with wide excision without radiation therapy.

To avoid dealing with the issue of local recurrence, it might be possible to determine patients who have a low risk of local recurrence after wide excision. Three factors appear to play a role. First is the size of the tumor. From the data in Table $2[1,2,5,10-14,20-22,27-40]$, it is apparent that patients with smaller tumors have a lower rate of recurrence. In general, for all patients, the rate is $20-40 \%$ with surgery alone, but is usually somewhat less if the tumor is smaller than $1 \mathrm{~cm}$. The NSABP B-23 study [10] looked at this issue specifically, comparing wide excision plus tamoxifen with wide excision and radiation \pm tamoxifen. Although the wide excision plus tamoxifen local control was statistically inferior to the radiation arms, the failure rate was only $14 \%$ with tamoxifen only. Interestingly, this was similar to the results of The Canadian study [11] in slightly larger tumors (up to $5 \mathrm{~cm}$ ). The Canadian study had an 8 year local failure rate of $17.6 \%$ with wide excision and tamoxifen. Surprisingly, the CALGB study [12] of patients over 70 years of age and tumors up to $4 \mathrm{~cm}$ showed at 5 years that patients in a similar arm (wide excision and tamoxifen) had only a $4 \%$ local failure. This brings up the second factor, that of patient age. The patients in the CALGB study were at least 70 years of age. In the Canadian study [11] when the subgroup of patients over the age of 60 years of age was analyzed, the local failure rate with tamoxifen alone dropped to $1.2 \%$. Several other studies have shown similar findings, some starting as young as the age of 50 years $[13,14]$. Veronesi found that with quadrantectomy alone, the local recurrence rate after age 55 dropped from $19 \%$ to $3 \%$ [15]. A
Swedish study demonstrated that the risk of recurrence after surgery alone decreases about $3 \%$ per year, with a 70 -yearold woman having half the recurrence rate of a 50 -year-old woman [14]. Some have shown that those patients are more likely to have grade 1-2 tumors rather than grade 3 tumors and are more likely to have estrogen receptor-positive tumors, factors that may account for the better outcome [5, 13]. Appropriately selected patients might have a low enough recurrence risk that they can avoid radiation. In one study [16] the ideal group was patients older than 50 years with grade 1-2 tumors smaller than $1.5 \mathrm{~cm}$ with excision margins of more than a $1 \mathrm{~cm}$. The local recurrence rate in that group of patients was $6 \%$. The third factor is that the wider the excision, the better the results, as evidenced by the better local control in the quadrantectomy patients [15].

One final consideration is the age and comorbid conditions of the patient. If a patient is going to die of other causes, then it is not necessary to eradicate every last cancer cell in the body. The goal should be to avoid over-treating the patient. The potential benefit of radiation is directly related to the life span of the patient. In our series, $6(9 \%)$ of the patients had an ipsilateral recurrence, but only $4 \%$ died of cancer and $64 \%$ died of other causes. Clearly the other causes were the overriding determinants of mortality, not the lack of radiation for breast cancer. Based on the work of Charlson [17], there have been numerous attempts to predict the impact of non cancer related comorbidities on mortality. Several studies have looked at comorbid conditions that predict for earlier death in elderly patients. One study [18] identified comorbid conditions such as heart disease, diabetes, other cancer, myocardial infarction, gallbladder, liver, and respiratory disease as clearly increasing non breast cancer mortality. The presence of three of these conditions was a greater predictor for mortality than advanced stage of breast cancer. A more recent study confirmed these findings. Breast cancer patients with severe comorbidity were twice as likely to die as those with none, independent of stage of disease [19]. While we cannot predict the patient's demise with any great accuracy, the greater the comorbid conditions, the less likely the patient is to benefit from post-excision radiation. While these approximations are still somewhat crude, they do give some indication that there are some breast cancer patients who can be treated "less aggressively."

There are two associated issues that are beyond an in depth review for this paper. The first is the issue of axillary dissection. This has been sited as an appropriate component of optimal treatment in the NCI consensus statement [4]. In our patients, only $24 \%$ underwent axillary dissection. The only axillary "recurrence" was in a patient who had palpable nodes at initial presentation. Others have detected a low rate of axillary recurrence without axillary dissection in older patients. The risk is less than $10 \%$ (range $0-18 \%$ ) [20-24]. It remains to be further elucidated, but avoiding axillary dissection with its attendant morbidity in this group of patients warrants consideration. The evolution of sentinel lymph node sampling has presented a reasonable option in this regard.

The second issue is the impact of systemic therapy on the risk of ipsilateral recurrence. In the NSABP 06 study, adjuvant systemic therapy did not change the local recurrence rate in the surgery alone group [1]. In NSABP B23, tamoxifen did not 
Table 2. Studies with Local Surgery without Radiation. NSABP B-06 WE Alone Arm Showed a 39\% Local Recurrence Rate. The Failure Curve has a Steep Slope and then a Gradual Plateau. It Took 4 Years to See 70\% of the Failures, therefore we Included Studies Only if they had a Median Follow Up of Greater than 4 Years

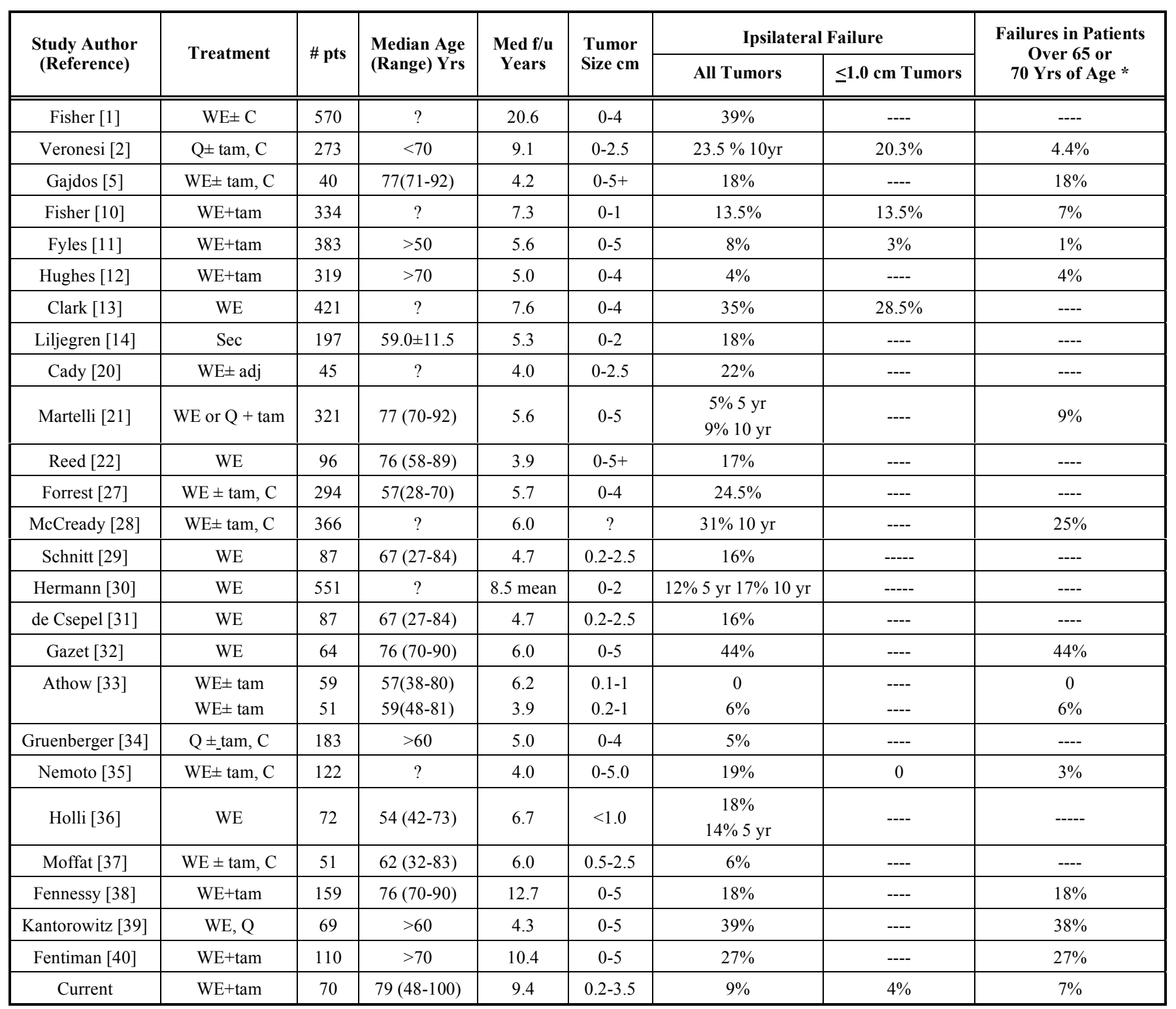

*Some studies used age 65 years and some age 70 years.

$\mathrm{WE}=$ Wide excision/lumpectomy, $\mathrm{Q}=$ quadranectomy, $\mathrm{Sec}=$ sector resection, Tam $=$ tamoxifen, $\mathrm{C}=$ chemotherapy, adj=adjuvant not specified, $\mathrm{LR}=\mathrm{local} / \mathrm{regional}$ recurrence. $\mathrm{All}$ others: ipsilateral breast recurrence.

result in the same control rate as radiation, but the recurrence rate was low. The Canadian study was similar, but the CALGB study showed a very low local recurrence rate ( $4 \%$ at 5 years) with tamoxifen. The issue is not clear, but at least intuitively we would expect chemotherapy or hormonal therapy to increase local control. Some have concluded that there is a benefit [5, 25]. Most studies like ours are difficult to interpret in that regard.

The fundamental question remains: are patients going to suffer from their cancer if they are not given post lumpectomy radiation? There have been some attempts using the data to model the risk. In a pooled analysis of 15 identifiable randomized studies [26], it was acknowledged that none of those studies showed a survival advantage to adding radiation to local surgery. Pooling the data found an $18 \%$ incidence of local recurrence (vs $6 \%$ in the radiation group), with an $8.6 \%$ excess mortality. Another study [25], using Markov modeling suggested a somewhat lower risk. For an 80-year-old woman on tamoxifen with an excised tumor up to $2 \mathrm{~cm}$ in size, the benefit to adding radiation therapy changed the risk of dying from cancer from $2.02 \%$ to $1.17 \%$. Stated another way, giving the radiation added an average 0.04 years of life (for a 75-year-old it was 0.09 years). There was a continued decrease in benefit for radiation therapy for every year older at diagnosis. Following these criteria, the risk of life-threatening recurrence is less than $5 \%$. Our data confirms this.

From the available data, it would appear that there are factors that predict for a low risk of dying of breast cancer. These factors appear to be additive. They are smaller tumors, 
wider excision margins, lower grade, elderly patients, patients with comorbid conditions, and adding tamoxifen.

Given these considerations, there are patients that can be managed with wide excision alone.

\section{REFERENCES}

[1] Fisher B, Anderson S, Bryant J, et al. Twenty-year follow-up of a randomized trial comparing total mastectomy, lumpectomy, and lumpectomy plus irradiation for the treatment of invasive breast cancer. N Engl J Med 2002; 347: 1233-41.

[2] Veronesi U, Marubini E, Mariani L, et al. Radiotherapy after breastconserving surgery in small breast carcinoma: long-term results of a randomized trial. Ann Oncol 2001; 12:997-1003.

[3] Swanson GP, Rynearson K, Geyer CE Jr, et al. Breast conservation in the treatment of breast cancer: community based experience. South Med J 2001; 94: 287-92.

[4] NIH Consensus conference: Treatment of Early-stage Breast Cancer. JAMA 1991; 265: 391-5.

[5] Gajdos C, Tartter PI, Bleiweiss IJ, et al. The consequence of undertreating breast cancer in the elderly. J Am Coll Surg 2001; 192: 698-707.

[6] Bouchardy C, Rapiti E, Fioretta G, et al. Undertreatment strongly decreases prognosis of breast cancer in elderly women. J Clin Oncol 2003; $21: 3580-7$.

[7] Balducci L. Ageism is alive and well: a call for action. Am J Oncol Rev 2004; 3: 263-5

[8] Hebert-Croteau N, Brisson J, Latreille J, et al. Compliance with consensus recommendations for the treatment of early stage breast carcinoma in elderly women. Cancer 1999; 85: 1104-13.

[9] Lazovich DA, White E, Thomas DB, et al. Underutilization of breastconserving surgery and radiation therapy among women with stage I or II breast cancer. JAMA 1991; 266: 3433-8.

[10] Fisher B, Bryant J, Dignam JJ, et al. Tamoxifen, radiation therapy, or both for prevention of ipsilateral breast tumor recurrence after lumpectomy in women with invasive breast cancers of one centimeter or less. J Clin Oncol 2002; 20: 4141-9.

[11] Fyles AW, McCready DR, Manchul LA, et al. Tamoxifen with or without breast irradiation in women 50 years of age or older with early breast cancer. N Engl J Med 2004; 35: 963-70.

[12] Hughes KS, Schnaper LA, Berry D, et al. Lumpectomy plus tamoxifen with or without irradiation in women 70 years of age or older with early breast cancer. N Engl J Med 2004; 35: 971-7.

[13] Clark R, Whelan T, Levine M, et al. Randomized clinical trial of breast irradiation following lumpectomy and axillary dissection for nodenegative breast cancer: an update. J Natl Cancer Inst 1996; 88: 1659-64.

[14] Liljegren G, Lindgren A, Bergh J, et al. Risk factors for local recurrence after conservative treatement in stage I breast cancer. Definition of a subgroup not requiring radiotherapy. Ann Oncol 1997; 8: 235-41.

[15] Veronesi U, Banfi A, Salvadori B, et al. Breast conservation is the treatment of choice in small breast cancer: long-term results of a randomized study. Eur J Cancer 1990; 26: 668-70.

[16] Lee SH, Chung MA, Chelmow D, et al. Avoidance of adjuvant radiotherapy in selected patients with invasive breast cancer. Ann Surg Oncol 2004; 1: 316-21.

[17] Charlson ME, Pompei P, Ales KL, et al. A new method of classifying prognostic comorbidity in longitudinal studies: development and validation. J Chronic Dis 1987; 40: 373-83.

[18] Satariano W, Ragland D. The effect of comorbidity on 3-year survival of women with primary breast cancer. Ann Intern Med 1994; 120: 10410.

[19] Piccirillo JF, Tierney RM, Costas I, et al. Prognostic importance of comorbidity in a hospital-based cancer registry. JAMA 2004; 291: 2441-2.

[20] Cady B, Stone MD, Wayne J. New therapeutic possibilities in primary invasive breast cancer. Ann Surg 1993; 218: 338-49.
[21] Martelli G, DePalo G, Rossi N, et al. Long-term follow-up of elderly patients with operable breast cancer treated with surgery without axillary dissection plus adjuvant tamoxifen. Br J Cancer 1995; 72: 1251-5.

[22] Reed MW, Morrison JM. Wide local excision as the sole primary treatment in elderly patients with carcinoma of the breast. Br J Surg 1989; 76: 898-900.

[23] Naslund E, Fernstad R, Ekman S, et al. Breast cancer in women over 75 years: is axillary dissection always necessary? Eur J Surg 1996; 162: 867-71.

[24] Fisher B, Redmond C, Fisher ER, et al. Ten-year results of a randomized clinical trial comparing radical mastectomy and total mastectomy with or without radiation. N Engl J Med 1985; 312: 67481.

[25] Punglia RS, Kuntz KM, Lee JH, et al. Radiation therapy plus tamoxifen versus tamoxifen alone after breast-conserving surgery in postmenopausal women with stage I breast cancer: a decision analysis. J Clin Oncol 2003; 21: 2260-7.

[26] Vinh-Hhung V, Verschraegen C. Breast-conserving surgery with or without radiotherapy: pooled-analysis for risks of ipsilateral breast tumor recurrence and mortality. J Natl Cancer Inst 2004; 96: 115-21.

[27] Forrest AP, Stewart HJ, Everington D, et al. Randomised controlled trial of conservation therapy for breast cancer: 6-year analysis of the Scottish trial. Lancet 1996; 348: 708-13.

[28] McCready DR, Chapman JA, Wall JL, et al. Characteristics of local recurrence following lumpectomy for breast cancer. Cancer Invest 1994; 12: 568-73.

[29] Schnitt SJ, Hayman J, Gelman R, et al. A prospective study of conservative surgery alone in the treatment of selected patients with stage I breast cancer. Cancer 1996; 77: 1094-1100.

[30] Hermann RE, Esselstyn CB Jr, Grundfest-Broniatowski S, et al. Partial mastectomy without radiation is adequate treatment for patients with stages 0 and I carcinoma of the breast. Surg Gynecol Obst 1993; 177: 247-53.

[31] de Csepel J, Tartter PI, Gajdos C. When not to give radiation therapy after breast conservation surgery for breast cancer. J Surg Oncol 2000; 74: $273-7$.

[32] Gazet JC, Ford HT, Coombes RC, et al. Prospective randomized trial of tamoxifen $v s$ surgery in elderly patients with breast cancer. Eur J Surg Oncol 1994; 20: 207-14.

[33] Athow AC, Gattuso JM, Perry N, et al. Is radiotherapy needed after breast conservation for small invasive breast cancers? Eur J Surg Oncol 2002; 28: 379-82.

[34] Gruenberger T, Gorlitzer M, Soliman, et al. Is it possible to omit postoperative irradiation in a highly selected group of elderly breast cancer patients? Breast Cancer Res Treat 1998; 50: 37-46.

35] Nemoto T, Patel JK, Rosner D, et al. Factors affecting recurrence in lumpectomy without irradiation for breast cancer. Cancer 1991; 67: 2079-82.

[36] Holli K, Sarristo R, Isola J, et al. Lumpectomy with or without postoperative radiotherapy for breast cancer with favourable prognostic features: results of a randomized study. Br J Cancer 2001; 84: 164-9.

[37] Moffat FL, Ketcham AS, Robinson DS, et al. Segmental mastectomy without radiotherapy for T1 and small T2 breast carcinomas. Arch Surg 1990; 125: 364-9.

[38] Fennessy M, Bates T, MacRae K, et al. Late follow-up of a randomized trial of surgery plus tamoxifen versus tamoxifen alone in women aged over 70 years with operable breast cancer. Br J Surg 2004; 91: 699-704.

[39] Kantorowitz DA, Poulter CA, Sischy B, et al. Treatment of breast cancer among elderly women with segmental mastectomy or segmental mastectomy plus postoperative radiotherapy. Int J Radiat Oncol Biol Phys 1988; 15: 263-70.

[40] Fentiman IS, van Zijl J, Karydas I, et al. Treatment of operable breast cancer in the elderly: a randomised clinical trial EORTC 10850 comparing modified radical mastectomy with tumorectomy plus tamoxifen. Eur J Cancer 2003; 39: 300-8. 